\title{
Cervical pedicle screws fixation treatment the atlantoaxial instability of axis burst fractures
}

Denglu Yan ( $\square$ yandenglu@163.com )

People's Hospital of Liuzhou

\section{Zaiheng Zhang}

Shenzhen Bao An Peoples Hospital

\section{Zhi Zhang}

Third Affiliated Hospital of Guangzhou Medical College

\section{Research}

Keywords: Axis, Fracture, Treatment, Fixation, Pedicle, Screw

Posted Date: February 18th, 2020

DOI: https://doi.org/10.21203/rs.2.23830/v1

License: (c) (i) This work is licensed under a Creative Commons Attribution 4.0 International License. Read Full License 


\section{Abstract}

\section{Background}

Although the cervical pedicle screws and rods were used for atlantoaxial instable, the axis fractures still a challenge for spine surgeon.

\section{Objective}

This study was to evaluated the clinical outcomes of axis burst fractures had C1C3 pedicles screws fixation treatment.

\section{Methods}

From June 2014 to July 2018, 45 patients with axis fractures were enrolled in this study; 23 patients was odontoid underwent $\mathrm{C} 1 \mathrm{C} 2$ pedicles screws fixation, and 21 patients was odontoid combine body fractures had C1C3 pedicles screws fixation. The clinical outcomes of pain relief (visual analog scale, VAS), functional disability (neck disability index, NDI) were recorded at baseline and at the final follow-up.

\section{Results}

The pain index and NDI were all significantly improved when compared to pretreatment $(P<0.01)$. The VAS and ND were no significant difference between two groups $(P>0.05)$. All patients, suffered from severe mechanical upper cervical neck pain at pre-operative, were pain free post-operation. Pre-operative neurological examination was normal in all patients, and remained the same after surgery. All cases showed normal neurological function at the final follow-up. No vascular or neurological complication was noted. The fracture healing and the bony union of the fixed segments were revealed in all cases on CT views. Implant failure and instability were not seen on lateral flexion/extension radiographs of the cervical spine.

\section{Conclusions}

Cervical pedicle screws fixation was effective and safe procedures in the treatment of traumatic spondylolisthesis of axial fractures. The atlantoaxial instable of axis burst fractures can be managed with C1-C3 pedicles screws fixation.

\section{Background}

The atlantoaxial complex bears approximately $50 \%$ of rotary motion and $12 \%$ of flexion and extension movement of the cervical spine.[1-4] The atlantoaxial joint was superior articular processes of $\mathrm{C} 2$ articulate with the inferior articular process of $\mathrm{C} 1$, which allow for rotation around the dens. Axis (C2) is a unique vertebra in that it serves as the transition from the upper cervical spine to the lower cervical spine. $[5,6]$ However, the stability of atlantoaxial complex relies solely on the atlantoaxial joint and the 
transverse ligament. Then, any injury of structure above may cause atlantoaxial instability, which was common in the odontoid fractures and pedicles fractures of axis, as well as axial body fractures.[7-10]

As an process of axis, odontoid fractures are very common, accounting for 18 to $20 \%$ of cervical injuries, of which 65 to $74 \%$ are type II fractures of Anderson and D'Alonzo classification. Type II fractures involve the base of the odontoid and do not extend into the $\mathrm{C} 2$ body and unstable associated with a nonunion rate of at least $32 \%$ with nonoperative treatment.[11-13] Odontoid fractures can causes the atlantoaxial instability, which may cause neck pain and stiffness, activity limitation, and progressive compression of the spinal cord.[14, 4, 15] As another special fractures of axis, Hangman's fractures was the pedicles fractures of $C 2$ which may led to traumatic spondylolisthesis of the axis.[16, 17] Levin and Edwards classified the $\mathrm{C} 2$ pedicles fractures into four types, and unstable fractures indicated for surgery.[18-20] Therefore, recovering normal anatomical position within a short period of time and maintaining its stability are needed for the treatment of atlantoaxial instability to prevent further spinal cord injury.

Unlike odontoid fractures and hangman's fractures, axial body fractures are uncommon and have a variety of presentations. Although some axial fractures can be healed with nonoperative management, sequelae of varying degrees of nuchal pain because of malalignment and osteoarthrosis of the atlantoaxial joint were common.[10, 19] Then, the current trend is surgical treatment in patients to align and stabilize the upper cervical spine protecting the neural elements. Due to axis specificity in structure and position, the axial body fractures still present a challenge for spinal surgeon. However, there are little paper about it in literature. The purpose of this study was to evaluate the clinical outcomes and efficacy of cervical pedicle screws fixation in the treatment of atlantoaxial instability of axis burst fractures.

\section{Materials And Methods}

From June 2014 to July 2018, 56 axis fractures patients with neurologically intact were enrolled in this study. All patients were diagnosed on the basis of clinical symptoms, X-rays of the cervical spine, computer tomography (CT), and magnetic resonance imaging (MRI). All patients were categorized into two groups, 35 patients was odontoid fractures or pedicle fractures were underwent C1C2 pedicles screws fixation (C1C2 group, included 13 men and 8 women with an average age of $38.74 \pm 9.65$ years), and 21 patients was axis body fractures had C1C3 pedicles screws fixation (C1C3 group, included 9 men and 6 women with an average age of $39.28 \pm 7.36$ years). The inclusion criteria were odontoid type II and type III fractures, C2 pedicle fractures, odontoid combine hangman fractures or body fractures; the .

Exclusion criteria included pathologic conditions of the cervical spine (trauma, tumor, or infection). The injury times were $3.56 \pm 1.73$ day in $\mathrm{C} 1 \mathrm{C} 2$ patients, and $3.14 \pm 1.62$ days in $\mathrm{C} 1 \mathrm{C} 3$ patients. There were no significant difference among three group in age and sex distribution, older and the pain history $(P>0.05)$. 
Table 1 General date of patients (Means \pm SD)

\begin{tabular}{|c|c|c|c|c|c|c|}
\hline Group & Gend & & Age & $\mathrm{He}$ & ation levels & Injury times \\
\hline & Male & Female & (Years) & TA & Fall & (days) \\
\hline C1C2 (35) & 19 & 16 & $38.74 \pm 9.65$ & 14 & 21 & $3.56 \pm 1.73$ \\
\hline C1C3 (21) & 12 & 9 & $39.28 \pm 7.36$ & 8 & 13 & $3.14 \pm 1.62$ \\
\hline
\end{tabular}

Note: $\mathrm{TA}=$ Traffic accidents

\section{Surgical procedures}

After general anesthesia, patient in the prone position. Based on the nature of the $\mathrm{C} 2$ fracture, skull traction was performed and preliminary fracture reduction was achieved by maximal cervical flexion or extension in accordance with the direction of fracture displacement. $\mathrm{C} 1, \mathrm{C} 2$, and $\mathrm{C} 3$ pedicle screw insertion was performed through the posterior approach as previously described.[21,22,4] To make sure that the screw and bone were appropriately fixed, X-ray and CT scans were performed. Finally, the wound was rinsed and the incisions closed. Patients were allowed to walk with a soft cervical collar at least four weeks post- operatively.

\section{Critical of clinical outcomes}

Before surgery and at the one year follow-up, operation times, blood loss, hospital stays, pain relief (visual analog scale, VAS), functional disability (neck disability index, NDI) were used to evaluate patient function. Furthermore, postoperative radiographs, CT, and MRI scans of the cervical spine were obtained for all patients and bone fusion was used as a means of radiological assessment.

\section{Statistical analysis}

All measurements were performed by a single observer and are expressed as means \pm SD. Using the SPSS 17.0 statistics software, classic t-test and chi-square test were performed.

\section{Results}

\section{Results}

There was no intraoperative death in this series. In ends 47 cases had follow-up at least one year and 9 cases lost, and the follow-up rate was $82.9 \%(29 / 35)$ in C1C2 pedicle screw fixation groups and $85.7 \%$ $(18 / 21)$ in $\mathrm{C} 1 \mathrm{C} 3$ pedicle screw fixation groups $(P>0.05)$. The followed time was from 13 to 16 months (average 14 months), and average $13.95 \pm 1.16$ months in $\mathrm{C} 1 \mathrm{C} 2$ pedicle screw fixation groups and 13.84 \pm 1.13 months in $\mathrm{C} 1 \mathrm{C} 3$ pedicle screw fixation groups $(P>0.05)$. 
Table 2 Follow up time and operation date of patients (Means \pm SD)

\begin{tabular}{llllll}
\hline Group & Follow up & & Operation time* & Blood loss* & Hospital days* \\
\cline { 2 - 4 } & Rate & Time (Month) & (Minutes) & $(\mathrm{mL})$ & (Days) \\
\hline C1C2 & $82.9 \%(29 / 35)$ & $13.95 \pm 1.16$ & $64.37 \pm 19.45$ & $148.75 \pm 32.46$ & $8.24 \pm 2.58$ \\
\hline C1C3 & $85.7 \%(18 / 21)$ & $13.84 \pm 1.13$ & $75.28 \pm 25.34$ & $165.23 \pm 36.81$ & $8.57 \pm 2.49$ \\
\hline
\end{tabular}

Note: $*$ No Significant difference $(\mathrm{P}>0.05)$

The average operational time, blood loose, and hospital days were showed in table 2. The operation time, blood loose and hospital days were similar between two groups and there were no significant difference $(P>0.05)$. The average operation time, blood loose and hospital days was $64.37 \pm 19.45$ minutes, 148.75 $\pm 32.46 \mathrm{~mL}$ and $8.24 \pm 2.58$ days in $\mathrm{C} 1 \mathrm{C} 2$ groups; $75.28 \pm 25.34$ minutes, $165.23 \pm 36.81 \mathrm{~mL}$ and $8.57 \pm$ 2.49 days in $\mathrm{C} 1 \mathrm{C} 3$ pedicle screw fixation groups.

Table 3 Clinical results date of patients (Means \pm SD)

\begin{tabular}{|c|c|c|c|c|}
\hline \multirow[t]{2}{*}{ Group } & \multicolumn{2}{|l|}{ C1C2* } & \multicolumn{2}{|l|}{ C1C3* } \\
\hline & Preoperative & Postoperative & Preoperative & Postoperative \\
\hline VAS & $8.72 \pm 1.13$ & $1.29 \pm 0.52$ & $8.69 \pm 1.24$ & $1.27 \pm 0.43$ \\
\hline NDI & $36.57 \pm 7.83$ & $2.56 \pm 0.27$ & $37.42 \pm 8.61$ & $2.48 \pm 0.34$ \\
\hline
\end{tabular}

The pain index and ODI were better all patients (Table 3). The VAS and ODI were significant better than preoperative $(P<0.01)$, and were no significant difference between two groups on the average change of VAS and ODI scores $(P>0.05)$. The VAS and ODI improved from $8.72 \pm 1.13$ to $1.29 \pm 0.52$ and $36.57 \pm$ 7.83 to $2.56 \pm 0.27$ in $\mathrm{C} 1 \mathrm{C} 2$ pedicle screw fixation groups, and from $8.69 \pm 1.24$ to $1.27 \pm 0.43$ and 37.42 \pm 8.61 to $2.48 \pm 0.34$ in $\mathrm{C} 1 \mathrm{C} 3$ groups.

All patients, suffered from severe mechanical upper cervical neck pain at pre-operative, were pain free post-operation. Pre-operative neurological examination was normal in all patients, and remained the same after surgery. All cases showed normal neurological function at the final follow-up. No vascular or neurological complication was noted. The fracture healing and the bony union of the fixed segments were revealed in all cases on CT views. Implant failure and instability were not seen on lateral flexion/extension radiographs of the cervical spine.

\section{Discussion}

Axis body fracture, as well as odontoid and pedicle fractures, may cause atlantoaxial instability which may cause neck pain and stiffness, activity limitation, and progressive compression of the spinal cord. $[23,24]$ Atlantoaxial instability caused by $\mathrm{C} 2$ fractures need surgical reduction and stabilization to limit the anterior displacement of atlas effectively and enhance the atlantoaxial sagittal stability to prevent further spinal cord injury.[25,14] Because of the anatomical peculiarity of the axis and the complexity of injury pathology, clinical management of the axis fractures was hard work for spine surgeon.[15] Among 
the treatment of axis fractures, the posterior pedicles screws fixation was preferred for its relative simple exposure with no major vascular and visceral structures. According to the data of this series, cervical pedicles screw fixation was safely performed in all patients, and there were no complications of nerve and vascular injury in this study cases.

The key to the surgical treatment of atlantoaxial instability caused by axis fractures is to reconstruct the axis structures.[20,26,5] The pedicle screw had the advantage not only at the solid fixation for bone fusion, but also at the active manipulation and reduction of atlantoaxial subluxation. $\mathrm{C} 1$ screws combined with separate instrumentation of $\mathrm{C} 2$ screws allow for the active manipulation and reduction in atlantoaxial luxation or subluxation.[27,16] In the situation of C2 body fractures and pedicle fractures, C3 pedicle screws was inserted in this series. $\mathrm{C} 3$ pedicle screws combined with $\mathrm{C} 1$ pedicle screws or lateral mass screw can work as a thoracolumbar spine pedicle screws fixation system and have shown obvious superiority in reduction the $\mathrm{C} 2$ body fractures. $[28,29]$ The results of all patients had bone fusion which shown $\mathrm{C} 1-\mathrm{C} 3$ cervical pedicle screw fixation stable and serve to transmit the weight of the cranium to caudally.

Atlantoaxial instable caused by odontoid type II and III fractures, pedicle fractures, and body fractures of axis, are usually suitable for surgical treatment.[30,31,5] Literature has mainly focused on axis fractures because the stability of this region is vital importance. Pedicles screw fixation surgery involves atlantoaxial fixation with an indirect attempt to reduce and fuse the fracture.[32-34] However, it carries the risks of injury to the vertebral arteries, hemorrhage from the paravertebral venous plexus and the C2 root ganglion. $[35,16]$ There were no intraoperative neurological and vascular injury in this series case, and no complication related to internal fixator was found. The data of this series suggest that preoperative imaging details, proper patient positioning, meticulous dissection, thorough anatomical knowledge and few added surgical nuances are the cornerstones in ideal pedicle screw placement.

Because conservative management of atlantoaxial instable caused by axis fractures has a high rate complication, for patients with atlantoaxial instable caused by odontoid type II and III fractures, pedicle fractures, and body fractures of axis, are usually suitable for surgical treatment, and the cervical pedicle screw fixation management is valuable for better clinical outcomes. Optimal treatment of axis fractures is controversial, further clinical series are needed to provide evidence for optimal management of axis fractures.

\section{Conclusion}

Cervical pedicle screws fixation was effective and safe procedures in the treatment of traumatic spondylolisthesis of axial fractures. The atlantoaxial instable of axis burst fractures can be managed with $\mathrm{C} 1-\mathrm{C} 3$ pedicles screws fixation.

\section{Declarations}




\section{Ethical approval and consent to participate}

This study was approved by the hospital ethics committee of the First People's Hospital of Zhaoqing, Zhaoqing City, Guangdong Province, and all patients signed had informed consent.

\section{Consent for publication}

Author Denglu Yan, Zaiheng Zhang, and Zhi Zhang all agree to publication.

\section{Availability of data and materials}

The datasets are available under reasonable request.

\section{Competing interests}

Author Denglu Yan, Zaiheng Zhang, and Zhi Zhang declare that they have no conflict of interest.

\section{Funding}

Not applicable of funding on this work.

\section{Authors' contributions}

DY participated in the design of the study and drafted the manuscript. ZZh participated in the design of the study and coordination and helped to draft the manuscript. ZZ participated in the design of the study and performed the statistical analysis. All authors read and approved the final manuscript.

\section{Author details}

${ }^{1}$ First People's Hospital of Zhaoqing, Zhaoqing, 526000, China

2 People's Hospital of Baoan, Shenzhen, 518101, China

${ }^{3}$ Third Hospital of Guangzhou Medical University, Guangzhou, 510150, China

\section{Acknowledgements}

We sincerely appreciated the genial help from all scholars who contributed to our research.

\section{Abbreviations}

VAS: visual analog scale

NDI: neck disability index

CT: computer tomography 
MRI: magnetic resonance imaging

\section{References}

1. Hu Y, Gu YJ, He XF, Xu RM, Ma WH, Zhao WD, Liang DZ, Zhong SZ (2010) Biomechanical evaluation of stability and three-dimensional movements of the atlantoaxial joint after artificial atlanto-odontoid joint arthroplasty. Orthop Surg 2 (2):111-118. doi:10.1111/j.1757-7861.2010.00073.x

2. Mashhadinezhad H, Samini F, Mashhadinezhad A, Birjandinejad A (2012) Clinical results of surgical management in type II odontoid fracture: a preliminary report. Turk Neurosurg 22 (5):583-587. doi:10.5137/1019-5149.JTN.5231-11.2

3. Tang X, Dong L, Tan M, Yi P, Yang F, Hao Q (2018) Long-Term Influence of C1-C2 Pedicle Screw Fixation on Occipitoatlantal Angle and Subaxial Cervical Spine in the Pediatric Population. Pediatr Neurosurg 53 (3):143-148. doi:10.1159/000481784

4. Goel A, Jain S, Shah A, Patil A, Vutha R, Ranjan S, More S (2018) Atlantoaxial Fixation for Odontoid Fracture: Analysis of 124 Surgically Treated Cases. World Neurosurg 110:558-567. doi:10.1016/j.wneu.2017.08.192

5. Evaniew N, Yarascavitch B, Madden K, Ghert M, Drew B, Bhandari M, Kwok D (2015) Atlantoaxial instability in acute odontoid fractures is associated with nonunion and mortality. Spine J 15 (5):910917. doi:10.1016/j.spinee.2014.03.029

6. Karamian BA, Campbell ST, Rinsky LA (2019) Complete Atlantoaxial Dislocation After Odontoid Synchondrosis Fracture: A 2-Year Follow-up Study: A Case Report. JBJS Case Connect 9 (2):e0327. doi:10.2106/JBJS.CC.18.00327

7. Riouallon G, Pascal-Moussellard H (2014) Atlanto-axial dislocation complicating a type II odontoid fracture. Reduction and final fixation. Orthop Traumatol Surg Res 100 (3):341-345. doi:10.1016/j.otsr.2013.12.026

8. Teo EC, Paul JP, Evans JH, Ng HW (2001) Biomechanical study of C2 (Axis) fracture: effect of restraint. Ann Acad Med Singapore 30 (6):582-587

9. Menger RP, Notarianni C (2019) C2 (Axis and Odontoid) Fractures. In: StatPearls. Treasure Island $(\mathrm{FL})$,

10. Pawar AY, O'Leary PF (2015) Combined Type II Odontoid Fracture with Jefferson's Fracture Treated with Temporary Internal Fixation. Asian Spine J 9 (6):966-970. doi:10.4184/asj.2015.9.6.966

11. Kim SK, Shin JJ, Kim TH, Shin HS, Hwang YS, Park SK (2011) Clinical outcomes of halo-vest immobilization and surgical fusion of odontoid fractures. J Korean Neurosurg Soc 50 (1):17-22. doi:10.3340/jkns.2011.50.1.17

12. Keskin F, Gomleksiz C, Sasani M, Oktenoglu T, Suzer T, Ozer AF (2014) Clinical results of anterior odontoid screw fixation for Type II odontoid fractures. Turk Neurosurg 24 (5):750-756.

doi:10.5137/1019-5149.JTN.9814-13.0 
13. Torregrossa F, Grasso G (2017) Conservative Management for Odontoid Cervical Fractures: Halo or Rigid Cervical Collar? World Neurosurg 97:723-724. doi:10.1016/j.wneu.2016.10.106

14. Ishak B, Schneider T, Gimmy V, Unterberg AW, Kiening KL (2018) A Modified Posterior C1/C2 Fusion Technique for the Management of Traumatic Odontoid Type II Fractures by Using Intraoperative Spinal Navigation: Midterm Results. J Orthop Trauma 32 (9):e366-e371. doi:10.1097/BOT.0000000000001241

15. Elliott MR, Kirkpatrick JS (2014) Type Ila Hangman's fracture with pure distraction: not your typical type lla fracture. Spine J 14 (7):1360-1361. doi:10.1016/j.spinee.2014.02.035

16. Duggal N, Chamberlain RH, Perez-Garza LE, Espinoza-Larios A, Sonntag VK, Crawford NR (2007) Hangman's fracture: a biomechanical comparison of stabilization techniques. Spine (Phila Pa 1976) 32 (2):182-187. doi:10.1097/01.brs.0000251917.83529.0b

17. de Ruiter GC, Arts MP (2016) Alternative approach in Type II hangman fractures. J Neurosurg Spine 24 (4):671-672. doi:10.3171/2015.7.SPINE15831

18. Park JH, Kim SH, Cho KH (2014) Clinical Outcomes of Posterior C2-C3 Fixation for Unstable Hangman's Fracture Compared with Posterior C1-C3 Fusion. Korean J Spine 11 (2):33-38. doi:10.14245/kjs.2014.11.2.33

19. Guo Q, Zhang M, Wang L, Lu X, Guo X, Ni B (2016) Comparison of Atlantoaxial Rotation and Functional Outcomes of Two Nonfusion Techniques in the Treatment of Anderson-D'Alonzo Type II Odontoid Fractures. Spine (Phila Pa 1976) 41 (12):E751-758. doi:10.1097/BRS.0000000000001370

20. Prost S, Barrey C, Blondel B, Fuentes S, Barresi L, Nicot B, Challier V, Lleu M, Godard J, Kouyoumdjian P, Lonjon N, Marinho P, Freitas E, Schuller S, Allia J, Berthiller J, Charles YP, French Society for Spine S (2019) Hangman's fracture: Management strategy and healing rate in a prospective multi-centre observational study of 34 patients. Orthop Traumatol Surg Res 105 (4):703-707. doi:10.1016/j.otsr.2019.03.009

21. Xu R, Ebraheim NA, Skie M (2008) Pedicle screw fixation in the cervical spine. Am J Orthop (Belle Mead NJ) 37 (8):403-408; discussion 408

22. Jeong DH, You NK, Lee CK, Cho KH, Kim SH (2013) Posterior C2-C3 Fixation for Unstable Hangman's Fracture. Korean J Spine 10 (3):165-169. doi:10.14245/kjs.2013.10.3.165

23. Clark S, Nash A, Shasti M, Brown L, Jauregui JJ, Mistretta K, Koh E, Banagan K, Ludwig S, Gelb D (2018) Mortality Rates After Posterior C1-2 Fusion for Displaced Type II Odontoid Fractures in Octogenarians. Spine (Phila Pa 1976) 43 (18):E1077-E1081. doi:10.1097/BRS.0000000000002637

24. Charles YP, Ntilikina Y, Blondel B, Fuentes S, Allia J, Bronsard N, Lleu M, Nicot B, Challier V, Godard J, Kouyoumdjian P, Lonjon N, Marinho P, Berthiller J, Freitas E, Barrey C (2019) Mortality, complication, and fusion rates of patients with odontoid fracture: the impact of age and comorbidities in 204 cases. Arch Orthop Trauma Surg 139 (1):43-51. doi:10.1007/s00402-018-3050-6

25. Reynolds JA, MacDonald JD (2016) Direct C2 Pedicle Screw Fixation for Axis Body Fracture. World Neurosurg 93:279-285. doi:10.1016/j.wneu.2016.06.047 
26. Faure A, Prost S, Mansouri N, Farah K, Blondel B, Fuentes S (2018) Odontoid Fracture in Patients Age $>75$ Years Surgically Managed by the Harms Technique: Bone Healing and 1-Year Mortality Rate in 57 Cases. World Neurosurg 116:e1087-e1091. doi:10.1016/j.wneu.2018.05.172

27. Salunke P, Karthigeyan M, Sahoo SK, Prasad PK (2018) Multiplanar realignment for unstable Hangman's fracture with Posterior C2-3 fusion: A prospective series. Clin Neurol Neurosurg 169:133138. doi:10.1016/j.clineuro.2018.03.024

28. Hu Y, Dong WX, Kepler CK, Yuan ZS, Sun XY, Zhang J, Xie H (2016) A Novel Anterior Odontoid Screw Plate for C1-C3 Internal Fixation: An In Vitro Biomechanical Study. Spine (Phila Pa 1976) 41 (2):E6472. doi:10.1097/BRS.0000000000001165

29. Liu J, Li Y, Wu Y, Zhu Q (2013) A novel method of cervical pedicle screw placement from C3 to C5 and its clinical applications. Spine (Phila Pa 1976) 38 (8):E504-512.

doi:10.1097/BRS.0b013e3182880065

30. Patibandla MR, Mudumba V, Yerramneni VK (2013) Double hangman's fracture. Spine (Phila Pa 1976) 38 (6):E374-377. doi:10.1097/BRS.0b013e318284362b

31. Bundoc RC, Delgado GG, Grozman SA (2017) A Novel Patient-Specific Drill Guide Template for Pedicle Screw Insertion into the Subaxial Cervical Spine Utilizing Stereolithographic Modelling: An In Vitro Study. Asian Spine J 11 (1):4-14. doi:10.4184/asj.2017.11.1.4

32. Takahata M, Yamada K, Akira I, Endo T, Sudo H, Yokoyama H, Iwasaki N (2018) A novel technique of cervical pedicle screw placement with a pilot screw under the guidance of intraoperative 3D imaging from C-arm cone-beam CT without navigation for safe and accurate insertion. Eur Spine J 27 (11):2754-2762. doi:10.1007/s00586-018-5706-x

33. Su P, Ma R, Li C, Liu S, Huang D (2007) Pedicle screw fixation of the cervical spine: guidance by computed tomography. Clin Orthop Relat Res 462:99-104. doi:10.1097/BL0.0b013e3180ebe4e5

34. Davidson CT, Bergin PF, Varney ET, Jones LC, Ward MS (2019) Planning C2 pedicle screw placement with multiplanar reformatted cervical spine computed tomography. J Craniovertebr Junction Spine 10 (1):46-50. doi:10.4103/jcvjs.JCVJS_116_18

35. Sheikh HQ, Athanassacopoulos M, Doshi AB, Breakwell L, Cole A, Rex Michael AL, Chiverton N (2018) Early mortality and morbidity following a type II odontoid fracture in the elderly. Surgeon 16 (5):297301. doi:10.1016/j.surge.2018.03.007

\section{Figures}




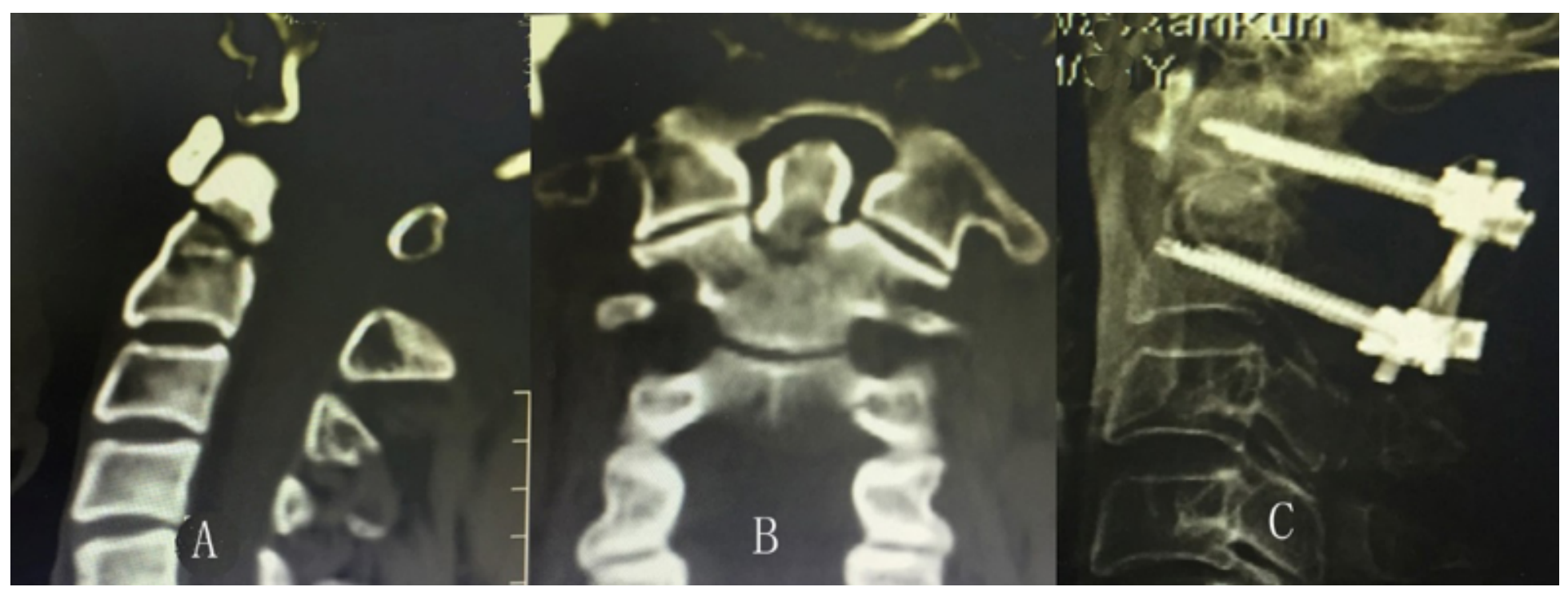

Figure 1

Male patient with 42 years old had odontoid type II fractures (A, B) were underwent C1-C2 pedicles screws fixation (C).

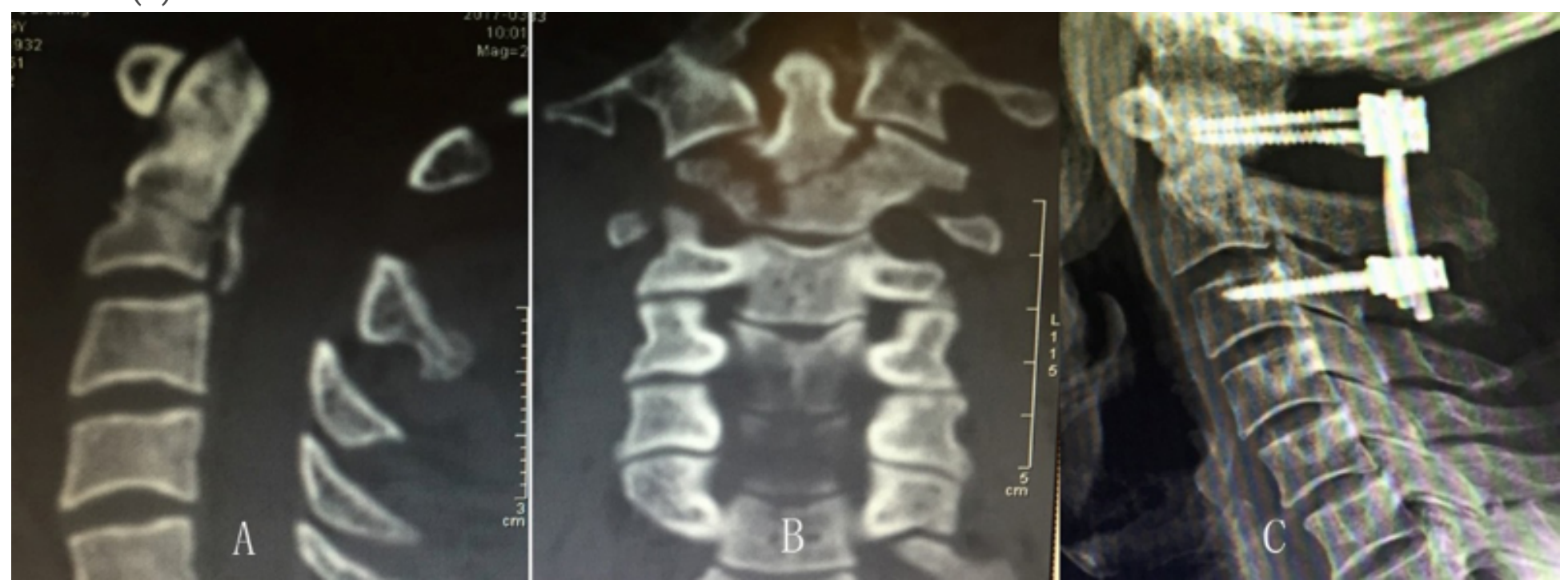

\section{Figure 2}

Male patient with 41 years old with axis body fractures (A, B) had C1-C3 pedicles screws fixation (C) 